\title{
Investigation of the Li-Ion Insertion Mechanism for Amorphous and Anatase $\mathrm{TiO}_{2}$ Thin-Films
}

\author{
S. Moitzheim, $\circledast^{1,2, *}$ S. De Gendt, $\oplus^{1,3, * *}$ and P. M. Vereecken ${ }^{1,2, * * *, z}$ \\ ${ }^{1}$ imec, B-3001, Belgium \\ ${ }^{2}$ KU Leuven, Department of Microbial and Molecular Systems, B-3001 Heverlee, Belgium \\ ${ }^{3}$ KU Leuven, Department of Chemistry, B-3001 Heverlee, Belgium
}

\begin{abstract}
Titania is considered an interesting anode candidate for $\mathrm{Li}^{+}$-ion batteries, as it offers a high theoretical capacity $\left(1280 \mathrm{mAh} \mathrm{cm}^{-3}\right.$ or $336 \mathrm{mAh} \mathrm{g}^{-1}$ ) and long term cycling stability. Unfortunately, the most commonly investigated anatase structure never reaches the theoretical capacity at practical charging rates (i.e. above $1 \mathrm{C})$. In this work, we compare amorphous $\left(\mathrm{am}-\mathrm{TiO}_{2}\right)$ to anatase $\mathrm{TiO}_{2}$ thin-films, and investigate the exceptional performance of $\mathrm{am}_{-} \mathrm{TiO}_{2}$ as $\mathrm{Li}^{+}$-ion insertion electrode. An in-depth electrochemical characterization using cyclic voltammetry $(\mathrm{CV})$, constant current lithiation and delithiation, and potentiostatic intermittent titration technique (PITT) is performed. From CV, the insertion and extraction kinetics of $\mathrm{am}-\mathrm{TiO}_{2}$ is found to be unrestricted by diffusion, contrary to anatase. Based on our combined electrochemical results, two different mechanisms are formulated for anatase and am$\mathrm{TiO}_{2}$. Whereas anatase is filled from the "top-down", with a buildup of Li near the electrode/electrolyte interface, am- $\mathrm{TiO}_{2}$ shows a "bottom-up" filling mechanism. This discrepancy is ascribed to the difference in diffusion coefficient measured for am- $\mathrm{TiO}_{2}$ and anatase. This work highlights the differences of $\mathrm{Li}$-ion insertion into amorphous $\mathrm{TiO}_{2}$ compared to anatase, and gives guidance on material development for high capacity and fast charging electrodes.

(C) The Author(s) 2019. Published by ECS. This is an open access article distributed under the terms of the Creative Commons Attribution 4.0 License (CC BY, http://creativecommons.org/licenses/by/4.0/), which permits unrestricted reuse of the work in any medium, provided the original work is properly cited. [DOI: 10.1149/2.1091816jes]

Manuscript submitted September 10, 2018; revised manuscript received November 30, 2018. Published January 2, 2019.

To meet the ever-growing demands for fast charging and high capacity energy storage, novel $\mathrm{Li}^{+}$-ion battery materials are continuously being developed. Specifically for the negative electrode, highrate performance materials are desired. As such, $\mathrm{TiO}_{2}$ is an intriguing material, as it is abundant, environmentally benign, stable and has a high theoretical capacity of $336 \mathrm{mAh} \mathrm{g}^{-1}$ or $1280 \mathrm{mAh} \mathrm{cm}^{-3}$. The most widely studied $\mathrm{TiO}_{2}$ structure is the anatase polymorph. $\mathrm{Li}^{+}$-ions can be inserted into $\mathrm{TiO}_{2}$ with the consecutive reduction of $\mathrm{Ti}(\mathrm{IV})$ to $\mathrm{Ti}(\mathrm{III})$ redox centers, given as:

$$
\mathrm{TiO}_{2}+x \mathrm{Li}^{+}+x \mathrm{e}^{-} \leftrightarrow \mathrm{Li}_{x} \mathrm{TiO}_{2}
$$

with $0 \leq \mathrm{x} \leq 1$. Unfortunately, bulk anatase exhibits a very poor rateperformance and in turn poor achievable capacity, with only about $770 \mathrm{mAh} \mathrm{cm}^{-3}$ (i.e. $\mathrm{x}=0.6$ or $200 \mathrm{mAh} \mathrm{g}^{-1}$ ) that can be achieved at very low charging rates $(<0.1 \mathrm{C})$. This poor performance is attributed to the combination of low electronic and ionic conductivity. There have been many strategies to achieve the full capacity $(\mathrm{x}=1)$ and fast charging, such as nanosizing, ${ }^{1,2}$ doping, ${ }^{3,4}$ or carbon composites..$^{5,6}$ Nevertheless, even for the best performing anatase $\mathrm{TiO}_{2}$ electrode, the capacity remains around $900 \mathrm{mAh} \mathrm{cm}^{-3}\left(235 \mathrm{mAh} \mathrm{g}^{-1}\right.$ or $\left.\mathrm{Li}_{0.7} \mathrm{TiO}_{2}\right)$ at a charging rate of $1 \mathrm{C}$, and quickly fades to $380 \mathrm{mAh} \mathrm{cm} \mathrm{cm}^{-3}$ $\left(100 \mathrm{mAh} \mathrm{g}^{-1}\right.$ or $\left.\mathrm{Li}_{0.3} \mathrm{TiO}_{2}\right)$ or below at rates of $10 \mathrm{C}$ and higher. ${ }^{1}$ To solve this, alternative $\mathrm{TiO}_{2}$ structures or polymorphs have been investigated (e.g. $\left.\mathrm{TiO}_{2}(\mathrm{~B})\right){ }^{7}$ Interestingly, amorphous $\mathrm{TiO}_{2}\left(\mathrm{am}-\mathrm{TiO}_{2}\right)$ was also shown to achieve a higher capacity and rate-performance compared to anatase..$^{8-10}$

In Table I, capacities for state-of-the-art $\mathrm{TiO}_{2}$ electrodes are given (see Ref. 11 for a more complete overview of state-of-the art capacities). It shows that almost double the capacity can be reached with am- $\mathrm{TiO}_{2}$ at a moderate charging rate of $3 \mathrm{C}$, while this becomes almost three-fold at a rate of $45 \mathrm{C}$ (for the nanotubes). $\mathrm{Am}_{-} \mathrm{TiO}_{2}$ was also combined with carbon nanosheets, ${ }^{12,13}$ carbon nanotubes, ${ }^{14}$ and carbon nanowires ${ }^{15}$ which resulted in high capacities and rate-performances. Interestingly, when using the amorphous structure, it seems that the rate-performance of $\mathrm{TiO}_{2}$ is generally enhanced compared to the crystalline structures, with capacities around $500 \mathrm{mAh} \mathrm{cm}{ }^{-3}$ (or $130 \mathrm{mAh} \mathrm{g}^{-1}$ ) for C-rates in the range of $40 \mathrm{C}^{8,9,13}$

At present, although nanoscale $\mathrm{am}-\mathrm{TiO}_{2}$ shows promising results, detailed electrochemical characterization of the underlying kinetics

\footnotetext{
*Electrochemical Society Student Member.

**Electrochemical Society Fellow.

****Electrochemical Society Member

${ }^{\mathrm{z}}$ E-mail: philippe.vereecken@imec.be
}

of $\mathrm{Li}^{+}$-ion insertion is lacking. Since it is often difficult to isolate the influence of electrode geometry (e.g. effective area, pore and particle size distribution, etc.) and electrode formulation (e.g. electronic additives and binder), the analysis of the underlying kinetics can be complex and ambiguous. To investigate the properties in a well-defined system, in this work, nanosized ( $\leq 35 \mathrm{~nm}$ ) planar thin-films of am- $\mathrm{TiO}_{2}$ and anatase were fabricated and characterized electrochemically. For the first time, nanosized am- $\mathrm{TiO}_{2}$ thin-films have been characterized and directly compared to anatase $\mathrm{TiO}_{2}$. Such am- $\mathrm{TiO}_{2}$ thin-films could be applied as an electrode for three-dimensional thin-film batteries, ${ }^{16}$ or as a surface protective coating for electrode particles (see e.g. Refs. 17 and 18).

As a deposition technique, atomic layer deposition (ALD) was used, which can deposit pin-hole free and uniform films over large surface areas with atom-level thickness control. By using different deposition precursors, amorphous and anatase films with controlled thickness were obtained. The structural and chemical composition was confirmed with grazing incidence X-ray diffraction (GI-XRD) and elastic recoil detection analysis (ERDA). The electrochemical properties of our nanoscaled amorphous and anatase $\mathrm{TiO}_{2}$ films were characterized systematically by cyclic voltammetry, galvanostatic charge/discharge and the potentiostatic intermittent titration technique (PITT). The PITT results were analyzed using a method of numerical inversion of Laplace Transforms, which allowed the extraction of underlying transport properties such as (the potential dependent) diffusion and

\begin{tabular}{cccc}
\hline $\begin{array}{l}\text { Table I. Examples of the capacity of state-of-the-art anatase and } \\
\text { amorphous } \mathrm{TiO}_{2} \text { structures. }\end{array}$ & $\begin{array}{c}\text { Gravimetric } \\
\text { capacity } \\
\left(\mathrm{mAh} \mathrm{g}^{-1}\right)\end{array}$ & $\begin{array}{c}\text { Volumetric } \\
\text { Capacity* } \\
\left(\mathrm{mAh} \mathrm{cm}^{-3}\right)\end{array}$ & C-rate $^{\phi}$ \\
Electrode & 150 & 570 & 3 \\
3D ordered microporous & 116 & 440 & 6 \\
anatase $^{1}$ & 111 & 420 & 3 \\
Vertically aligned anatase & 50 & 190 & 45 \\
nanotubes & & 870 & 3 \\
Vertically aligned amorphous & 229 & 610 & 45 \\
nanotubes & &
\end{tabular}

* Reports given in units of gravimetric capacity $\left(\mathrm{mAh} \mathrm{g}^{-1}\right)$ were converted to volumetric capacities $\left(\mathrm{mAh} \mathrm{cm}^{-3}\right)$ by assuming a density of $3.8 \mathrm{~g} \mathrm{~cm}^{-3}$.

${ }^{\phi} \mathrm{A}$ rate of $1 \mathrm{C}$ corresponds here to $336 \mathrm{~mA} \mathrm{~g}^{-1}$ or $1280 \mathrm{~mA} \mathrm{~cm}^{-3}$. 
charge transfer coefficients. Together with the different electrochemical techniques, the enhanced capacity and rate-performance of am$\mathrm{TiO}_{2}$ is explained, and two distinct $\mathrm{Li}^{+}$-ion insertion mechanisms for each structure are formulated.

\section{Material and Methods}

Substrate and $\mathrm{TiO}_{2}$ deposition.-300 $\mathrm{mm}$ TiN-coated $\mathrm{Si}$ wafers were used as substrate for the $\mathrm{TiO}_{2}$ films. Titanium nitride (TiN) was deposited on the Si substrate by ALD in a Pulsar 3000 reactor (ASM). Before deposition, the Si wafer was cleaned by an ozonated water rinse, followed by an $\mathrm{HF} / \mathrm{HCl}$ based etch. TiN was chosen as it functions as current collector and diffusion barrier for lithium into the underlying Si. ${ }^{19}$ Anatase was deposited directly on full $300 \mathrm{~mm}$ TiN-coated $\mathrm{Si}$ wafers in the clean room. For am-TiO 2 , the TiN-coated $\mathrm{Si}$ wafers were manually cleaved in $2 \times 2 \mathrm{~cm}^{2}$ pieces. Amorphous and anatase $\mathrm{TiO}_{2}$ films were deposited by ALD using two different processes. $\mathrm{Am}-\mathrm{TiO}_{2}$ films were deposited from a tetrakis dimethylamido titanium $\left(\mathrm{Ti}\left(\mathrm{N}\left(\mathrm{CH}_{3}\right)_{2}\right)_{4}\right.$ or TDMAT) and water precursor at $100^{\circ} \mathrm{C}$ in a custom built ALD reactor. TDMAT and $\mathrm{H}_{2} \mathrm{O}$ were sequentially exposed to the TiN substrate for a total number of 700, 200 or $100 \mathrm{cy}$ cles, to deposit films with a nominal thickness of 35,10 and $5 \mathrm{~nm}$. The TDMAT process is chosen as it was known to form amorphous $\mathrm{TiO}_{2}$ at a deposition temperature of $100^{\circ} \mathrm{C} .{ }^{20}$ Anatase films were deposited at $250^{\circ} \mathrm{C}$ using $\mathrm{Ti}\left(\mathrm{OCH}_{3}\right)_{4}$ and $\mathrm{H}_{2} \mathrm{O}$ as precursors in a Pulsar 3000 reactor (ASM). A total number of 682 cycles (nominal thickness of $35 \mathrm{~nm}$ ) were adopted, which leads to polycrystalline anatase films. ${ }^{21}$ A short comparison between $\mathrm{H}_{2} \mathrm{O}$ and $\mathrm{O}_{3}$ as the oxygen source was made for anatase films in terms of electrochemical properties (see Figure S1). No significant difference was found between the two precursors, and $\mathrm{H}_{2} \mathrm{O}$ was chosen for the remainder of the work. The film thicknesses of the $35 \mathrm{~nm}$ anatase and $\mathrm{am}-\mathrm{TiO}_{2}$ films were confirmed using scanning electron microscopy (SEM). From ERDA experiments on $\mathrm{TiO}_{2} / \mathrm{TiN}$ samples, it was found that oxygen and carbon impurities were below 1 at.\% in the TiN layer (see Figure S2 for ERDA depth profile), and the compositions of the $\mathrm{TiO}_{2}$ films are given in the results section. The bulk resistivity of our ALD TiN was measured to be around $5 \times 10^{-6} \Omega \mathrm{m}$.

Structural and chemical characterization.-The amorphous nature of the am- $\mathrm{TiO}_{2}$ films and crystallinity of the anatase films were determined by grazing incidence X-ray diffraction (GI-XRD) and visualized with transmission electron microscopy (TEM). The film composition was determined with elastic recoil detection analysis (ERDA). GI-XRD was performed with an X-Pert PRO MRD (Panalytical), equipped with a $\mathrm{Cu} \mathrm{K} \alpha \mathrm{X}$-ray source. On the incident beam side, a graded parabolic mirror and a $1 / 32^{\circ}$ divergence slit were inserted, and on the diffracted side, a 0.04 rad Soller slit together with a parallel plate collimator. GI-XRD measurements were done at an incidence angle of $1^{\circ}$, and the signal was continuously recorded by scanning in the $2 \theta$ direction at a rate of $0.025^{\circ} \mathrm{s}^{-1}$. TEM was performed with a Titan G2 (FEI) at an operating voltage of $120 \mathrm{kV}$. For the TEM sample preparation, a spin-on-carbon and Pt capping layer was applied on top of the $\mathrm{TiO}_{2}$ layer, and a slice of this stack was removed by a focused ion beam for further analysis. For ERDA, a $\mathrm{Cl}^{4+}$ ion beam is accelerated to an energy of $8.0 \mathrm{MeV}$, and impinged onto the sample, using a scatter angle of $40.5^{\circ} .^{22,23}$ Either incident ions elastically scattered from atoms in the sample, or host atoms elastically recoiled from the sample are detected by a time-of-flight energy telescope. The kinetic energy as well as the speed (time-of-flight) of each atom reaching the detector allows for the identification of the corresponding element in the film. For the analysis, the signal from recoiled atoms were used for all elements except titanium, which is determined from scattered $\mathrm{Cl}^{4+}$. More information of our ERDA setup can be found in Ref. 14.

Electrochemical characterization.-A custom-made threeelectrode polytetrafluoroethylene (PTFE) cell was used which is clamped onto the substrate using a Kalrez O-ring (exposed surface
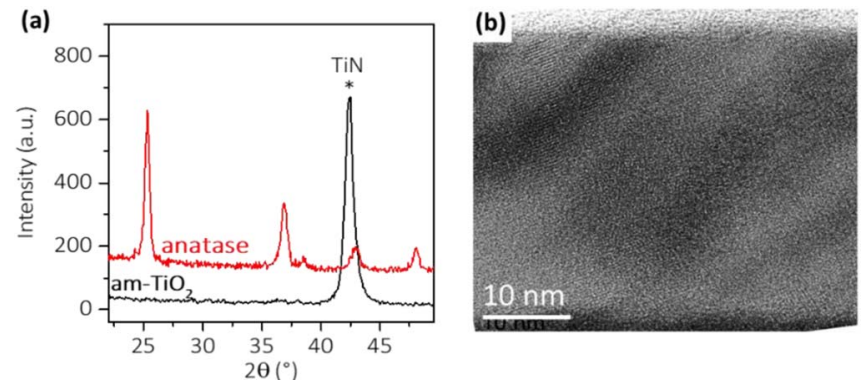

(c)

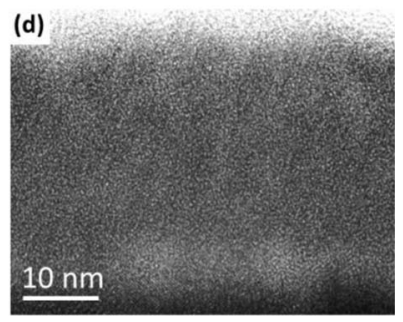

Figure 1. (a) Grazing incidence $\mathrm{XRD}$ of $35 \mathrm{~nm}$ am- $\mathrm{TiO}_{2}$ and anatase films. Star denotes the signal from the TiN current collector. TEM image of an anatase $\mathrm{TiO}_{2}$ film as deposited (b), an am- $\mathrm{TiO}_{2}$ film as deposited (c), and an am- $\mathrm{TiO}_{2}$ film after electrochemical testing (d).

area of $\left.1.1 \mathrm{~cm}^{2}\right)$ and filled with a liquid electrolyte $(10-15 \mathrm{~mL})$. The substrate is sandwiched between a copper foil and the electrochemical cell (see Figure S3). The cell contains two compartments, into which Li metal strips were placed, and which served as the counter and reference electrode. The compartment with the Li reference electrode was connected to the main compartment through a Luggin capillary close to the surface of the working electrode (at $4 \mathrm{~mm}$ ). Electrical contact is made to the TiN current-collector by scratching the uncovered $(\mathrm{Si})$ side of the sample and applying a Ga-In eutectic paste on the back and edges of the sample, which is then in contact with the copper foil. Note that an O-ring seal prevents the electrolyte solution from contacting the $\mathrm{Si}$ substrate and $\mathrm{Cu} / \mathrm{Ga}-\mathrm{In} / \mathrm{TiN}$ current collectors (see Figure S3), thus preventing any insertion or alloying reactions to occur with these components. All experiments were performed at room temperature $\left(21^{\circ} \mathrm{C}\right)$ using a $\mathrm{LiClO}_{4}$ in propylene carbonate (PC) electrolyte solution. For ease of preparation, an ampoule containing $\mathrm{LiClO}_{4}$ (100 g, battery grade, dry, 99.99\%, Sigma Aldrich) was dissolved in propylene carbonate $(100 \mathrm{~mL}, 99.7 \%$, Sigma Aldrich), which results in a $0.94 \mathrm{M}$ solution. The substrate edges were softly scratched and covered with a silver paste to contact the TiN current collector. Measurements were done in an Ar filled glove box with $\mathrm{O}_{2}$ and $\mathrm{H}_{2} \mathrm{O}$ levels below $1 \mathrm{ppm}$. The electrochemical cell was controlled through a PGSTAT101 Autolab (Metrohm) potentiostat/galvanostat, using the Nova 1.10 software. Cyclic voltammetry was performed between 1.0 $\mathrm{V}$ and $3.2 \mathrm{~V}$ or 0.1 and $3.2 \mathrm{~V}$, with scan rates ranging from $1 \mathrm{mV} \mathrm{s}^{-1}$ to $100 \mathrm{mV} \mathrm{s}^{-1}$. Constant current lithiation and delithiation experiments were done with charging rates (C-rate) between $1 \mathrm{C}$ and $500 \mathrm{C}$. A rate of $1 \mathrm{C}$ is based on the theoretical capacity of anatase as determined from the Ti content from ERDA and by assuming the reduction of Ti(IV) to Ti(III). PITT was performed in the voltage range of 3.0-1.0 $\mathrm{V}$, with potential step increments of $\pm 10 \mathrm{mV}$. Each consecutive step was applied after a cutoff current of $\pm 0.44 \mu \mathrm{A} \mathrm{cm}^{-2}(\sim 0.1 \mathrm{C})$ was reached. All potentials are given $v \mathrm{Li}^{+} / \mathrm{Li}$.

\section{Results}

Structure and composition.-The crystallinity of the $\mathrm{TiO}_{2}$ films was examined by GI-XRD (Figure 1a). The $35 \mathrm{~nm}$ anatase film show the characteristic diffraction peaks for the (101), (103) and (200) crystal planes, at $2 \vartheta$ angles of $25.3^{\circ}, 36.8^{\circ}$ and $48.1^{\circ}$, respectively. On the other hand, the $35 \mathrm{~nm}$ am- $\mathrm{TiO}_{2}$ film is devoid of clear features, besides a peak related to the TiN current collector at $42.5^{\circ}$, which 
Table II. Composition of the $35 \mathrm{~nm}$ anatase and am- $\mathrm{TiO}_{2}$ films as determined by ERDA. The maximum capacity is calculated from the Ti content by assuming a complete reduction of $\mathrm{Ti}(\mathrm{IV})$ to $\mathrm{Ti}$ (III).

\begin{tabular}{ccc} 
& Anatase & am- $\mathrm{TiO}_{2}$ \\
\hline $\mathrm{H}($ at.\%) & 0.4 & 6.9 \\
$\mathrm{C}($ at.\%) & 0.3 & 2.0 \\
$\mathrm{~N}($ at.\%) & 0.1 & 2.2 \\
$\mathrm{O}($ at.\%) & 61.9 & 55.6 \\
$\mathrm{Ti}($ at.\%) & 37.3 & 33.3 \\
Ti content $\left(10^{15} \mathrm{at.} \mathrm{cm}^{-2}\right)$ & 97 & 61 \\
Max. capacity $\left(\mathrm{mAh} \mathrm{cm}^{-3}\right)$ & 1230 & 770
\end{tabular}

confirms the amorphous nature of the $\mathrm{TiO}_{2}$ film. TEM analysis of anatase and $\mathrm{am}-\mathrm{TiO}_{2}$ films was also performed. Figure $1 \mathrm{~b}$ shows the as-deposited anatase thin-film. The polycrystalline anatase structure is clearly revealed. Crystalline grains are detected that span the full thickness of the $\mathrm{TiO}_{2}$ layer and are 50 to $100 \mathrm{~nm}$ in length. Lattice distances obtained after Fast Fourier transform of crystalline regions were matched to the anatase structure. Cross-sectional TEM images of am- $\mathrm{TiO}_{2}$ were made for as-deposited films (Figure 1c) and for samples after electrochemical testing (Figure 1d). Both for as-deposited and electrochemically cycled am- $\mathrm{TiO}_{2}$, the structure is seen to be mainly amorphous. Only for a few images, some small crystalline regions were detected $(<5 \mathrm{~nm})$, and were indexed to a rutile $\mathrm{TiO}_{2}$ structure. Overall the am- $\mathrm{TiO}_{2}$ samples are amorphous and remained so even after electrochemical cycling.

The compositions determined by ERDA of the $35 \mathrm{~nm}$ films are given in Table II. For the anatase film, the O:Ti ratio is 1.7, which shows that the films are oxygen deficient. Also, hydrogen, carbon and nitrogen contamination are below 0.4 at. $\%$. For the $\mathrm{am}-\mathrm{TiO}_{2}$ film, an $\mathrm{O}: \mathrm{Ti}$ atomic ratio of 1.7 is also measured. In this case, several at.\% of hydrogen, carbon and nitrogen impurities are detected, which likely originate from incomplete removal or partial decomposition of the $-\mathrm{N}\left(\mathrm{CH}_{3}\right)_{2}$ ligand during the deposition.

The total Ti content for $\mathrm{am}-\mathrm{TiO}_{2}$ is considerably lower than that of the anatase film even though they have the same thickness, indicating a lower density of the amorphous film. Based on the Ti content, the density for the anatase film was calculated at $3.7 \mathrm{~g} \mathrm{~cm}^{-3}$, which is close to the theoretical density of $3.8 \mathrm{~g} \mathrm{~cm}^{-3},{ }^{24}$ and $2.3 \mathrm{~g} \mathrm{~cm}^{-3}$ for am- $\mathrm{TiO}_{2}$. Assuming that $1 \mathrm{Li}$ per $\mathrm{Ti}$ can be inserted (i.e. reduction from $\mathrm{Ti}(\mathrm{IV})$ to $\mathrm{Ti}(\mathrm{III})$ ), this corresponds to a maximum capacity of 1230 and $770 \mathrm{mAh} \mathrm{cm}^{-3}$ (i.e. $336 \mathrm{mAh} \mathrm{g}^{-1}$ ) for these anatase and am- $\mathrm{TiO}_{2}$ films, respectively.

Cyclic voltammetry study of $\mathrm{Li}^{+}$-ion insertion and extraction.For the first electrochemical tests, cyclic voltammetry (CV) measurements were done in two different potential ranges: $3.2-1.0 \mathrm{~V}$, and $3.2-0.1 \mathrm{~V}$. Fresh anatase and $\mathrm{am}-\mathrm{TiO}_{2}$ films (35 nm thickness) were cycled three times in these potential ranges (Figure 2). During the first three cycles in Figure 2a, anatase films shows a typical reduction peak around $1.6 \mathrm{~V}$, which corresponds to $\mathrm{Li}^{+}$-ion insertion (Eq. 1). A small shoulder is apparent after the peak at $1.6 \mathrm{~V}$, which is also typically seen for anatase $\mathrm{TiO}_{2}{ }^{25}$ For subsequent cycles in the same potential range, the current in the cathodic region slightly diminishes, which can be attributed to the reduction of surface bound water or decomposition of the electrolyte solution. On the anodic side, a peak around 2.2 and $2.4 \mathrm{~V}$ is measured, for the anatase samples scanned to 1.0 and $0.1 \mathrm{~V}$, respectively, which is attributed to $\mathrm{Li}^{+}$-extraction. Scanning to $0.1 \mathrm{~V}$ results in lower peak current densities for lithiation and delithiation, and shifts the delithiation peaks to a higher potential. On the other hand, from the charge measured during the cathodic and anodic scans, it is found that approximately $30 \%$ more lithium can be inserted and extracted into anatase when scanning to $0.1 \mathrm{~V}$. Interestingly, when more lithium is inserted, the delithiation potential is shifted to higher values with broadening of the anodic peak, which suggests a more sluggish delithiation kinetics.

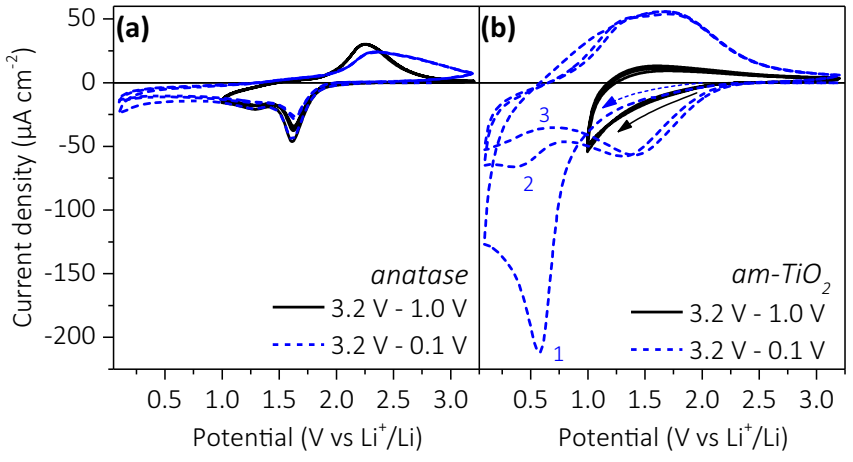

Figure 2. Cyclic voltammograms of $35 \mathrm{~nm}$ anatase (a) and $\mathrm{am}-\mathrm{TiO}_{2}$ (b) films cycled 3 times in the range of $3.2-1.0 \mathrm{~V}$, and $3.2-0.1 \mathrm{~V}$ at $10 \mathrm{mV} \mathrm{s}^{-1}$. Measurements were done in a three-electrode setup using a Li metal counter and reference electrode, and a $1 \mathrm{M} \mathrm{LiClO}_{4}$ in $\mathrm{PC}$ electrolyte solution.

The $\mathrm{CV}$ scans for am- $\mathrm{TiO}_{2}$ show a quite different behavior compared to anatase (Figure 2b) and the selected potential range now affected the shape of the voltammogram. Am- $\mathrm{TiO}_{2}$ cycled down to $1.0 \mathrm{~V}$ showed no clear peak features in both the cathodic and anodic regions. Subequent scans did not alter the current response. However, when scanned down to $0.1 \mathrm{~V}$ the am- $\mathrm{TiO}_{2}$ was activated with a large cathodic peak at $0.57 \mathrm{~V}$ in the first scan. In the reverse scan, a broad anodic peak at $1.6 \mathrm{~V}$ for delithiation of $\mathrm{am}-\mathrm{TiO}_{2}$ film is observed, which returns reproducibly in the following scans. Interestingly, from the second cycle on, a reproducible cathodic peak also appears at $1.5 \mathrm{~V}$ and is attributed to $\mathrm{Li}^{+}$-ion insertion upon reduction of Ti(IV) to $\mathrm{Ti}(\mathrm{III})$. The peak around $0.57 \mathrm{~V}$ is still present, albeit $200 \mathrm{mV}$ shifted more negative and quickly reduces in intensity upon cycling. A much larger capacity of $-1170 \mathrm{mAh} \mathrm{cm}^{-3}$ under the cathodic peak at $0.5 \mathrm{~V}$ in the first scan versus the $+600 \mathrm{mAh} \mathrm{cm}^{-3}$ in the anodic scan, points to an irreversible component in the first activation scan. At this point, the exact reaction is unclear, however it must involve some transformation of the amorphous material as merely the formation of an SEI layer cannot explain the activation behavior. Activation of amorphous ALD deposited thin films has been observed also for other material systems. ${ }^{26,27}$ For the remainder of the CV analysis, a voltage range of 3.2-0.1 V was adopted.

To further investigate the lithium insertion and extraction kinetics, additional $\mathrm{CV}$ experiments of $35 \mathrm{~nm}$ am- $\mathrm{TiO}_{2}$ and anatase films were performed in the 3.0-0.1 V range at varying scan rates between 1 and $100 \mathrm{mV} \mathrm{s}^{-1}$ (Figure 3). The 10, 20, 50 and $100 \mathrm{mV} \mathrm{s}^{-1}$ scans are shown for am- $\mathrm{TiO}_{2}$ (Figure 3a) and anatase (Figure 3b) films. Note that since am- $\mathrm{TiO}_{2}$ resulted in higher current densities, the scale of the "current density" axis for am- $\mathrm{TiO}_{2}$ (Figure 3a) is four times larger than for anatase (Figure $3 \mathrm{~b}$ ). First, the peak potential as a function of scan rate is examined for $\mathrm{am}_{-} \mathrm{TiO}_{2}$ (Figure 3c), and anatase (Figure 3d). For am$\mathrm{TiO}_{2}$, at low scan rate, the lithiation and delithiation peak potentials are very close, $(1.75 \mathrm{~V}$ for lithiation and $1.81 \mathrm{~V}$ for delithiation at $1 \mathrm{mV}$ $\left.\mathrm{s}^{-1}\right)$, with an average peak potential, $U_{\mathrm{av}}=\left(U_{\text {lith }}+U_{\text {delith }}\right) / 2$, of 1.78 $\mathrm{V}$. The average potential of $\mathrm{am}-\mathrm{TiO}_{2}$ is very near the average potential measured with PITT (see next section), which is about $1.77 \mathrm{~V}$. The average peak potential at low scan rates corresponds to the standard redox potential of the insertion/extraction reactions. Upon increasing the scan rate, mostly the lithiation peak potential shifts to more negative values, which also shifts the average potential. Shifting peak potentials are related to overpotentials induced by charge-transfer resistance and other ohmic resistances such as the ionic and electronic resistance of the electrode. A shift in the average peak potential indicates that the lithiation and delithiation reactions no longer follow Nernstian equilibrium conditions. For am- $\mathrm{TiO}_{2}$, the cathodic peak potentials shift significantly more than the anodic peak potentials, which shows that lithiation is more kinetically hindered than delithiation. The peak potentials of anatase (Figure $3 \mathrm{~d}$ ) are shifted compared to am- $\mathrm{TiO}_{2}$, with peak potential values at $1.69 \mathrm{~V}$ and $2.26 \mathrm{~V}\left(1 \mathrm{mV} \mathrm{s}^{-1}\right)$, 
(a)

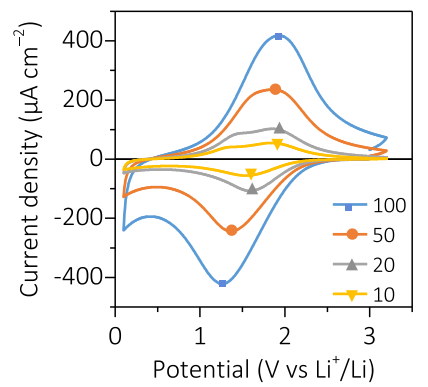

(c)

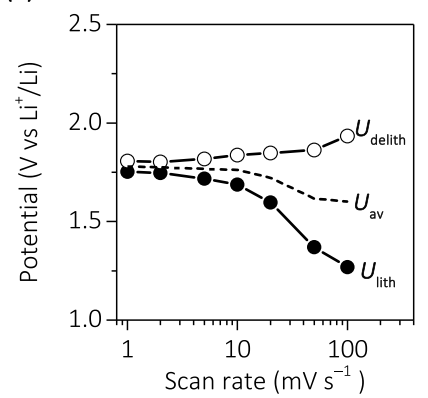

(b)

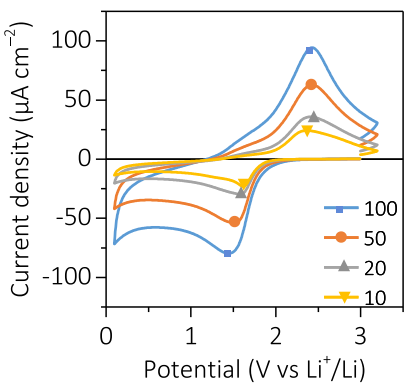

(d)

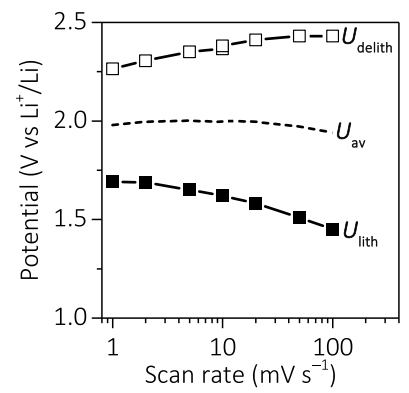

Figure 3. Cyclic voltammetry experiments of $35 \mathrm{~nm}$ am- $-\mathrm{TiO}_{2}$ and anatase films. Scans recorded at 10, 20, 50 and $100 \mathrm{mV} \mathrm{s}^{-1}$ are shown for am- $\mathrm{TiO}_{2}$ (a) and anatase (b). The peak potential as a function of scan rate for am- $\mathrm{TiO}_{2}$ (c) and anatase (d). The films were cycled between 3.2 and $0.1 \mathrm{~V}$.

for lithiation and delithiation, respectively. The crystalline anatase has potentials determined by a two-phase transformation equilibrium ${ }^{28}$ whereas amorphous titania follows Nernstian behavior as for solid solutions. Indeed, there is a significant separation in the cathodic and anodic peak potential of about $0.57 \mathrm{~V}\left(\right.$ at $1 \mathrm{mV} \mathrm{s}^{-1}$ ) for anatase, whereas this is only few tens of millivolts $(\sim 50 \mathrm{mV})$ for am- $\mathrm{TiO}_{2}$. The average peak potential (standard redox potential) of anatase at this low scan rate $(1.98 \mathrm{~V})$ is about $0.2 \mathrm{~V}$ more positive than for $\mathrm{am}-\mathrm{TiO}_{2}$ $(1.8 \mathrm{~V})$ showing that they have different thermodynamic properties as well.

The scan rate dependence of the lithiation peak currents $\left(i_{\mathrm{p}, \text { lith }}\right)$ for amorphous and anatase films are investigated in Figure $4 \mathrm{a}$. In general, the peak current density for am- $\mathrm{TiO}_{2}$ is higher than anatase. Importantly, the peak currents for am- $\mathrm{TiO}_{2}$ are linearly dependent with scan rate (i.e. a slope of 1.0 in the $\log -\log$ plot), while anatase shows a near-square root dependency (i.e. a slope of 0.58). Hence, insertion is not limited by solid-state diffusion for am- $\mathrm{TiO}_{2},\left(i_{\mathrm{p}, \text { lith }} \propto \nu\right)$, while it

(a)

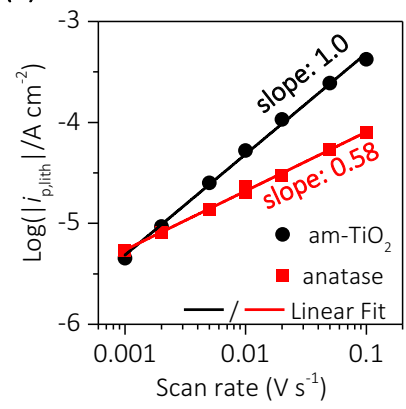

(b)

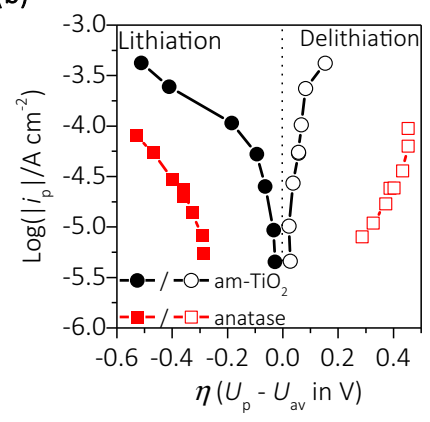

Figure 4. The logarithm of (lithiation) peak currents vs scan rate (a), and (lithiation and delithiation) peak currents vs overpotential (b) for $35 \mathrm{~nm}$ am$\mathrm{TiO}_{2}$ and anatase films. The overpotential was calculated by subtracting the lithiation and delithiation peak potentials with the average potential. The electrodes were cycled between 3.2 and $0.1 \mathrm{~V}$.

(a)

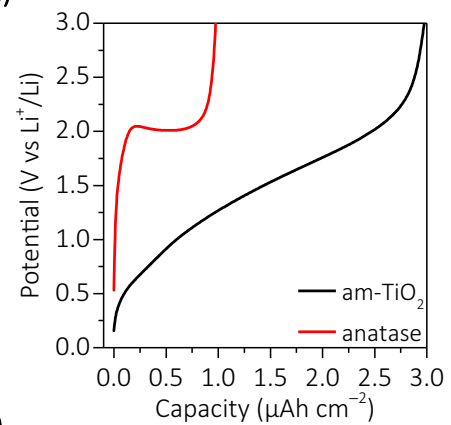

(b)

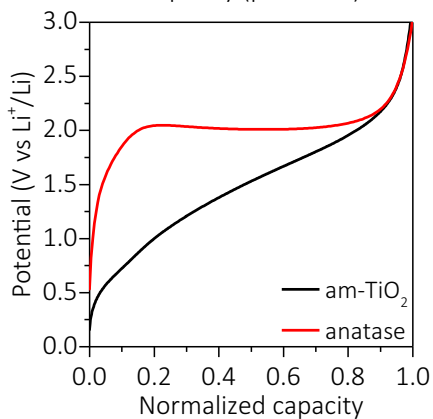

(c)

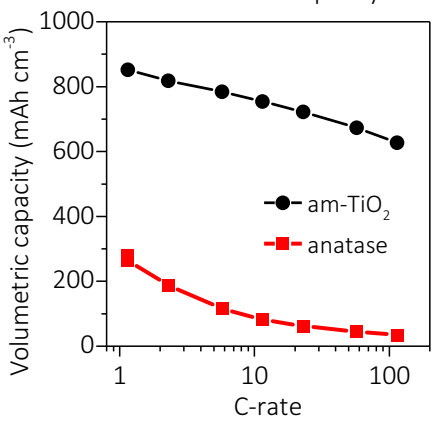

Figure 5. Charge/discharge experiments for $35 \mathrm{~nm}$ anatase and am- $\mathrm{TiO}_{2}$ films. (a) The potential vs capacity during delithiation for anatase and am$\mathrm{TiO}_{2}$. (b) The potential vs normalized capacity (i.e. the capacity divided by the total capacity reached at $3.0 \mathrm{~V}$ ). (c) The volumetric capacity of anatase and am- $\mathrm{TiO}_{2}$ as a function of C-rate. A rate of $n \cdot \mathrm{C}$ corresponds to $n \cdot 4.3$ $\mu \mathrm{A} \mathrm{cm}^{-2}$. The cutoff voltages were 0.1 and $3.0 \mathrm{~V}$, for lithiation and delithiation, respectively.

is for anatase $\left(i_{\mathrm{p}, \text { lith }} \propto \sqrt{\nu}\right) \cdot{ }^{29,30}$ This suggests that the average $\mathrm{Li}^{+}$-ion diffusion coefficient is higher for am- $\mathrm{TiO}_{2}$ than for anatase, since the maximum diffusion distance for $\mathrm{Li}^{+}$-ions is the same in both films. The behavior of the diffusion coefficient as a function of electrode potential will be analyzed in more detail by PITT in the next section. The peak currents were also plotted as a function of overpotential $(\eta)$ in Figure 4b. The lithiation and delithiation overpotentials were determined by subtracting the average or formal potential determined at the lowest scan rate from the measured peak potentials. The plot reveals that for both the lithiation and the delithiation reactions, am$\mathrm{TiO}_{2}$ requires a smaller overpotential to achieve a certain peak current, suggesting overall more facile kinetics compared to anatase.

Rate-performance probed by constant current charge/ discharge.-The rate-performance of the $35 \mathrm{~nm}$ anatase and am- $\mathrm{TiO}_{2}$ films were probed by constant current lithiation and delithiation experiments (Figure 5). Typical potential-capacity profiles for delithiation at $1 \mathrm{C}$ rate are shown in Figure 5a. The lithiation and delithiation steps were performed at the same current density or C-rate. The cutoff potential was $0.1 \mathrm{~V}$ and $3.0 \mathrm{~V}$ for lithiation and delithiation, respectively. For the analysis, only the delithiation curves were considered to assess the reversible charge stored. The potential-capacity profiles 


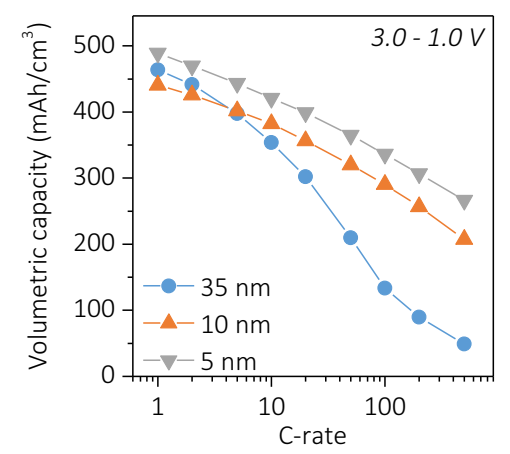

Figure 6. Volumetric (delithiation) capacity of 35,10 and $5 \mathrm{~nm}$ am- $\mathrm{TiO}_{2}$ films as a function of C-rate. A rate of $n \cdot \mathrm{C}$ corresponds to $n \cdot 4.3, n \cdot 1.2$ and $n \cdot 0.61$ $\mu \mathrm{A} \mathrm{cm}^{-2}$ for the 35,10 and $5 \mathrm{~nm}$ films, respectively. The rate-performance was measured in a custom built three-electrode cell.

of Figure 5a show quite some differences, and a significantly higher capacity for am- $\mathrm{TiO}_{2}$ compared to anatase.

For easier comparison of the potential profile shapes, we normalized the capacities to their maximum value upon reaching the cutoff potential (Figure 5b). The potential profile of anatase shows a clear plateau at $2.0 \mathrm{~V}$ typical for a two-phase transformation reaction, whereas am- $\mathrm{TiO}_{2}$ shows a sloped profile across the full potential range, resembling a a solid solution type insertion. Also, about $20 \%$ of the total $\mathrm{Li}^{+}$is inserted/extracted below $1.0 \mathrm{~V}$ for am- $-\mathrm{TiO}_{2}$, while only a small fraction is inserted below $1.0 \mathrm{~V}$ for anatase $\mathrm{TiO}_{2}$. The C-rate performance of $35 \mathrm{~nm}$ thick anatase and $\mathrm{am}-\mathrm{TiO}_{2}$ films is shown in Figure $5 \mathrm{c}$. At $1 \mathrm{C}$, anatase reaches $285 \mathrm{mAh} \mathrm{cm}^{-3}$ (i.e. $77 \mathrm{mAh} \mathrm{g}^{-1}$ or $\left.\mathrm{Li}_{0.24} \mathrm{TiO}_{2}\right)$, while am- $\mathrm{TiO}_{2}$ achieves $851 \mathrm{mAh} \mathrm{cm}{ }^{-3}\left(370 \mathrm{mAh} \mathrm{g}^{-1}\right.$ or $\mathrm{Li}_{1.1} \mathrm{TiO}_{2}$ ). The stoichiometry of $\mathrm{Li}_{1.1} \mathrm{TiO}_{2}$ for am- $\mathrm{TiO}_{2}$ could mean that more than $1 \mathrm{Li} / \mathrm{Ti}$ is inserted, or that ERDA slightly underestimated the Ti content (by 10\%). It is likely that the latter is the case, as it is known that the ERDA signal for Ti is less accurate than for the heavier elements (at least $4 \%$ error is expected). At a rate of $115 \mathrm{C}$, the accessible capacity for anatase decreases to $11 \%$ of the maximum capacity, whereas this is still $67 \%$ for am- $\mathrm{TiO}_{2}$; i.e. about 18 times higher. The enhanced rate performance of $\mathrm{am}-\mathrm{TiO}_{2}$ corroborates well the $\mathrm{CV}$ results.

The dependence of film thickness on the rate-performance was investigated for $\mathrm{am}-\mathrm{TiO}_{2}$ films only. Charge/discharge experiments were performed with 35,10 , and $5 \mathrm{~nm}$ thin $\mathrm{am}-\mathrm{TiO}_{2}$ films for $\mathrm{C}$-rates between $1-500 \mathrm{C}$ in the voltage range of 3.0-1.0 $\mathrm{V}$ to limit the background current which was most prominent for the thinnest film (Figure 6). For comparison, the $35 \mathrm{~nm}$ am- $\mathrm{TiO}_{2}$ films show a volumetric capacity of about $450 \mathrm{mAh} \mathrm{cm}^{-3}\left(196 \mathrm{mAh} \mathrm{g}^{-1}\right.$ or $\left.\mathrm{Li}_{0.58} \mathrm{TiO}_{2}\right)$ at $1 \mathrm{C}$ in this voltage range. Interestingly, the $35 \mathrm{~nm}$ films show a rapid drop in capacity for C-rates larger than $10 \mathrm{C}$ with only $10 \%$ of the maximum capacity remaining at $500 \mathrm{C}$. The thinnest films of 10 and 5 $\mathrm{nm}$ am- $\mathrm{TiO}_{2}$, on the other hand, show a smooth and gradual decrease in capacity with C-rate with $50 \%$ of the capacity remaining at $500 \mathrm{C}$. Hence, at these high $\mathrm{C}$-rates, the 5 and $10 \mathrm{~nm}$ have about 5 times the volumetric capacity of a $35 \mathrm{~nm}$ film.

The C-rate performance improves as the thickness of the films decreases. This follows from the shorter Li diffusion path for the thinner films. Whereas the CV results showed that the $35 \mathrm{~nm}$ films were not limited by bulk diffusion (determined by the peak current), the charge/discharge results show that the delithiation rate is still limited for currents $>40 \mu \mathrm{A} \mathrm{cm}^{-2}$. This indicates that diffusion may be still limiting at higher charges (Li loadings) than those at the peak current in the cyclic voltammograms. This can be illustrated when plotting the current against lithium loading obtained with the $\mathrm{CV}$ experiments (see Figure S4). Since the Li-ion transport properties depend on the Li content (see next section), it is possible that a $\mathrm{CV}$ can show no indication of diffusion limitation (i.e. at the peak current), whereas this is still observed in a charge/discharge experiment which probes a much wider capacity range.
The rate-performance of the 10 and $5 \mathrm{~nm}$ films is similar and the continuous change in Figure 6 indicates that the kinetics remains fast for all $\mathrm{Li}$ loadings. The mechanism for Li insertion and extraction will be discussed further on.

Determination of kinetic parameters by PITT.-The kinetics of the $35 \mathrm{~nm}$ am- $\mathrm{TiO}_{2}$ and anatase films was studied in more detail using potentiostatic intermittent titration technique (PITT). The electrode potential is stepped in small potential increments of $0.01 \mathrm{~V}$, and subsequent current transients are recorded until the new equilibrium Li-content at the new potential is reached. Since only a small perturbation is applied, the system can be considered in near-equilibrium state. PITT measurements were performed in the voltage range of 3.0$0.1 \mathrm{~V}$ for $\mathrm{am}-\mathrm{TiO}_{2}$ and 3.0-1.0 $\mathrm{V}$ for anatase as insertion/extraction is negligible for the latter below $1 \mathrm{~V}$ (see Figure 5a).

A series of current transients is shown for a selected potential range for am- $\mathrm{TiO}_{2}$ (Figure 7a) and anatase (Figure 7b). Overall, the current transients for $\mathrm{am}-\mathrm{TiO}_{2}$ and anatase show a quite different response. For am- $\mathrm{TiO}_{2}$ an exponential-like current decay is measured for each consecutive step over the whole potential range. For anatase, most of the current flows during a certain series of potential steps in a specific potential region. Furthermore, the current spikes are lower, and the time of subsequent steps varies considerably; i.e. from a few seconds to a few thousands seconds. During these long current transients, the current shows a phase nucleation-like behavior, which is marked by first a quick fall, then rise, and finally it falls again as it evolves over time. The incremental charge passed after each potential step is plotted against the electrode potential (Figures 7c-7d). For am- $\mathrm{TiO}_{2}$ (Figure 7c), lithium ions are inserted and extracted broadly across the whole potential range, with broad peaks centered at $1.77 \mathrm{~V}$ for both the incremental insertion and extraction capacity. The peak positions and shapes are very similar to those seen in the cyclic voltammograms and confirms a solid-solution type insertion-extraction. Below $0.5 \mathrm{~V}$ an irreversible charge is seen, which points to the contribution of electrolyte solution decomposition at these low potentials. For anatase (Figure 7d), most of the lithium ions are inserted at $1.78 \mathrm{~V}$ and extracted at $1.90 \mathrm{~V}$. This is a result of the sudden onset of phase transition between the lithium rich and lithium poor phase.

The potential-capacity profile is obtained from the integrated charge (vs applied potential) during the PITT experiment. The lithiumion content $\left(x\right.$ in $\mathrm{Li}_{\mathrm{x}} \mathrm{TiO}_{2}$ ) is shown as a function of potential for am- $\mathrm{TiO}_{2}$ in Figure 7e. The profile is similar to the one obtained during the charge/discharge experiment (see Figure 5a). A stoichiometry up to $\mathrm{Li}_{0.98} \mathrm{TiO}_{2}$ is obtained during lithiation. A discrepancy between the lithiation and delithiation charge is observed: only $0.87 \mathrm{Li} / \mathrm{Ti}$ is extracted during the delithiation step. This is likely attributed to the irreversible component introduced by the electrolyte decomposition at low potentials. There is also slightly less lithium inserted/extracted during PITT compared to the charge/discharge experiment. This could be attributed to some experimental error introduced by the low current (nA) measurements, or an internal self-discharge phenomenon related to the solvent/electrolyte decomposition at low voltage. Alternative, it is possible that lithiation/delithiation of $\mathrm{am}-\mathrm{TiO}_{2}$ at such a slow rate leads to some degradation of the material. The potential-capacity profile reproduced from the cumulated charge of the PITT experiment for anatase (Figure 7f) also matches our previous charge/discharge results (see Figure 5a). Lithium-ions are reversibly inserted/extracted up to $\mathrm{Li}_{0.44} \mathrm{TiO}_{2}\left(1.89 \mu \mathrm{Ah} \mathrm{cm} \mathrm{cm}^{-2}\right)$. In this case, a higher capacity was obtained for the PITT experiment. Since the charge/discharge experiments for anatase were likely diffusion limited at $1 \mathrm{C}$, it follows that the slower PITT enabled more $\mathrm{Li}^{+}$-ions to be inserted/extracted. It is known that the amount of solid-solution insertion into anatase (before phase transition occurs) depends on its particle size. ${ }^{31}$ In our case, the $\mathrm{Li}$-insertion proceeds up to a stoichiometry of $\mathrm{Li}_{0.034} \mathrm{TiO}_{2}$ before phase transition occurs at $1.78 \mathrm{~V}$. This is similar to what Wagemaker et al. have shown for bulk anatase particles (i.e. $120 \mathrm{~nm}$ in size). ${ }^{31}$ From previous reports, the phase transition results in an orthorhombic $\mathrm{Li}_{0.5} \mathrm{TiO}_{2}$ phase. In our case, after the nucleation-like current transient (i.e. below $1.78 \mathrm{~V}$ ), an average stoichiometry of $\mathrm{Li}_{0.12} \mathrm{TiO}_{2}$ is 

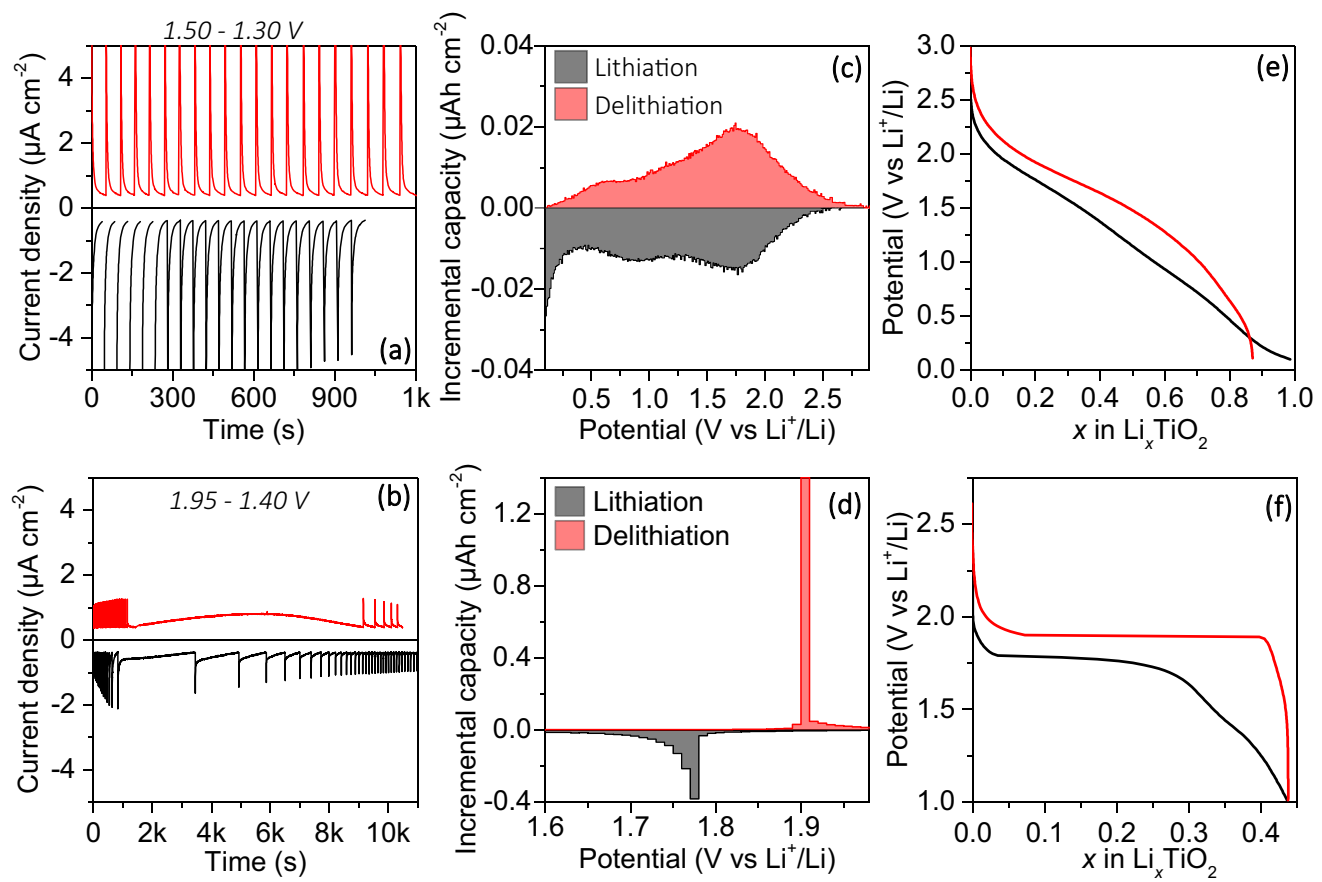

Figure 7. PITT experiments of lithiation (black) and delithiation (red) of $35 \mathrm{~nm}$ am- $\mathrm{TiO}_{2}$ (a,c,e) and anatase (b,d,f) films. A selection of current transients in the potential range of 1.30 to $1.50 \mathrm{~V}$ for am- $-\mathrm{TiO}_{2}$ (a), and 1.40 to 1.95 for anatase (b) are shown. The time was shifted so that $t=0$ equals the first point in the potential range of interest. The incremental capacity measured after each potential step is plotted vs the potential (c,d). The capacity (given as $x$ in $\left.\mathrm{Li}_{x} \mathrm{TiO}_{2}\right)$ is plotted vs. the potential (e,f). For the PITT experiments, a potential step of $\pm 0.01 \mathrm{~V}$ was applied until a cutoff current of $\pm 0.44 \mu \mathrm{A} \mathrm{cm}{ }^{-2}$ was reached.

obtained for anatase, suggesting that not all crystallites transformed to the $\mathrm{Li}_{0.5} \mathrm{TiO}_{2}$ phase. At the end of lithiation (at $1 \mathrm{~V}$ ), the stoichiometry reaches $\mathrm{Li}_{0.44} \mathrm{TiO}_{2}$.

By analyzing the current transients, information on the nearequilibrium transport properties can be obtained. ${ }^{32}$ Analytical solutions to the current transient are available for simple cases, for example based on assumptions of only semi-infinite diffusion (i.e. Cottrell equation), ${ }^{33,34}$ or finite-length diffusion with or without inclusion finite reaction kinetics. ${ }^{35,36}$ Often, graphical methods are used to determine diffusion time constants by finding maxima in $I t^{1 / 2}$ vs $t$ plots (the "Cottrellian region"). ${ }^{32}$ The graphical method can be expanded to include effects of slow reaction kinetics by plotting $\left(I t^{1 / 2}\right)^{-1}$ vs $t^{-1 / 2}$ for example, and fitting a linear function to the short time domain. ${ }^{37} \mathrm{~A}$ problem that arises with such graphical methods, is the often arbitrary selection of the timespan used for fitting and oversimplification of underlying transport phenomena. A slightly more complicated, but vastly more powerful method, is the use of numerical inversion of Laplace transforms (NILT), as shown for example by Montella et al. ${ }^{38-40}$ With this method, equivalent circuit models typically used for electrochemical impedance fitting can be transformed from the frequency domain to the time domain, and subsequently fitted by standard non-linear regression of $I$ vs $t$ data (see Figure 8). For example, NILT of the Warburg diffusion impedance is equivalent to the Cottrell equation. The advantage is that any arbitrary model expressed in terms of Laplace functionals can be used, and that the complete time domain can be represented (as opposed to the graphical methods). As the algorithm for NILT, the Gaver-Stehfest method ${ }^{38}$ is used and implemented in the Mathematica software package, ${ }^{41}$ together with a non-linear regression procedure.

All models suggested in Ref. 42 were tested with our data, such as the model representing finite reaction kinetics together with finitelength Warburg diffusion (FLW) or anomalous diffusion (trapping and release of ions). The model that best fitted our current transients $(0.005<\chi 2<0.1$ for $I$ vs $t$ in $\mu \mathrm{A})$, is shown in the inset in Figure 8 . This relatively simple model consists of a "internal" resistor $\left(R_{\Omega}\right)$, Warburg diffusion element $(W)$ and intercalation capacitance $\left(C_{\text {int }}\right)$ in series. $R_{\Omega}$ is the sum of charge-transfer resistance $\left(R_{\mathrm{ct}}\right)$, series resis- tance $\left(R_{\mathrm{s}}\right)$ and electronic resistance of $\mathrm{TiO}_{2}$ itself $\left(R_{\mathrm{e}}\right)$. From separate experiments, the series resistance is found to be below $100 \Omega \mathrm{cm}^{2}$. The Warburg diffusion element has the Warburg coefficient, $\sigma_{\mathrm{W}}$, which, together with the intercalation capacitance $\left(C_{\mathrm{int}}\right)$ is used to determine the diffusion coefficient. The intercalation capacitance is defined as: ${ }^{32}$

$$
C_{i n t}=\Delta q / \Delta U
$$

where $\Delta q$ is the incremental charge density integrated under the current transient and $\Delta U$ the applied potential step. $C_{\text {int }}$ can either be determined as a fitting parameter, or directly by measuring the charge from the $I$ vs $t$ plot and dividing by the potential step. As a selfconsistency check, the fitted value of $C_{\text {int }}$ should be about the same as the measured one. In our case, the fitted $C_{\text {int }}$ was about 1 to 4 times higher than the experimental one (see Figure S5), which is a relatively good match. The diffusion coefficient is given by: ${ }^{35}$

$$
D=\frac{l^{2}}{\left(\sigma_{\mathrm{W}} C_{\mathrm{int}}\right)^{2}}
$$

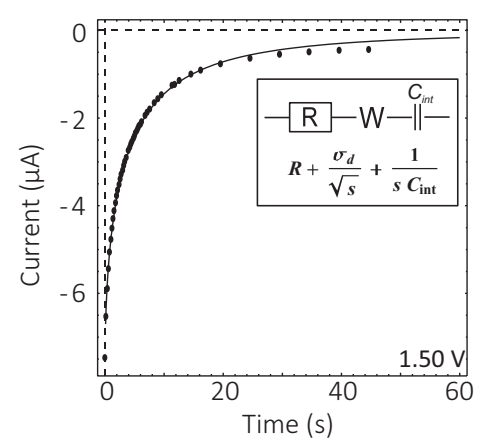

Figure 8. Example of a current transient of $35 \mathrm{~nm}$ am- $\mathrm{TiO}_{2}$ film stepped from $1.51 \mathrm{~V}$ to $1.50 \mathrm{~V}$. The solid line shows the fitted model based on the equivalent circuit (inset) transformed from the s-domain to the time domain using NILT. For this fit, a $\chi^{2}$ value of 0.090 (for $I$ vs $t$ in $\mu$ A) was obtained. 
(a)

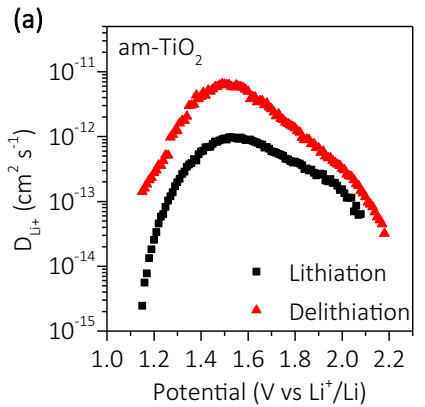

(b)

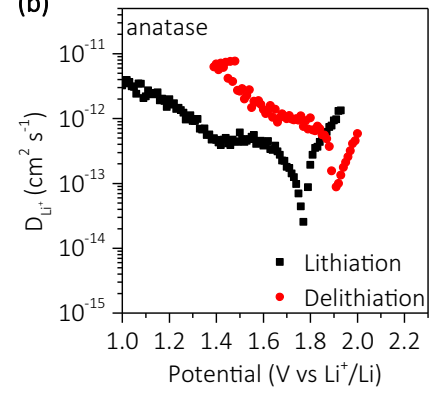

Figure 9. Diffusion coefficients obtained after fitting current transients using models obtained from NILT. The diffusion coefficients are based on the Warburg coefficient and intercalation capacitance, and given as a function of electrode potential for $35 \mathrm{~nm}$ thick am- $\mathrm{TiO}_{2}$ (a) and anatase (b) films.

with $l$ the thickness of the electrode film. This model was successfully applied to the current transients of lithium insertion and extraction in our am- $\mathrm{TiO}_{2}$ films in the voltage range of 3.0-1.0 V. For anatase $\mathrm{TiO}_{2}$, the same model was used, but with omission of $C_{\text {int }}$, as reliable values could not be obtained. In this case, the following analytical solution is available: ${ }^{43}$

$$
I(t)=\frac{\Delta U}{R_{\Omega}} \exp \left(\frac{\sigma_{\mathrm{W}}^{2}}{R_{\Omega}^{2}} t\right) \operatorname{erfc}\left(\frac{\sigma_{\mathrm{W}}}{R_{\Omega}} \sqrt{t}\right)
$$

with fitting parameters $R_{\Omega}$ and $\sigma_{\mathrm{W}}$ as given above. Using the fitting procedures introduced above, $R_{\Omega}, \sigma_{\mathrm{W}}$ and $C_{\text {int }}$ were determined (see Figure S5-6) and the chemical diffusion coefficient as a function of electrode potential was determined using Eq. 3 for am-TiO (Fig- $^{-}$ ure $9 \mathrm{a}$ ) and anatase (Figure 9b). Note that for anatase, the previously discussed phase nucleation-like transients are not described by the models introduced above, and are therefore omitted from the analysis (i.e. at 1.78 for lithiation and 1.90 for delithiation).

From Figure 9a, the diffusion coefficient of am- $\mathrm{TiO}_{2}$ is shown to vary between $10^{-11}$ and $10^{-15} \mathrm{~cm}^{2} \mathrm{~s}^{-1}$ depending on the electrode potential. Specifically, maxima in diffusion coefficient near $1.5 \mathrm{~V}$ of $1 \times 10^{-12} \mathrm{~cm}^{2} \mathrm{~s}^{-1}$ and $6 \times 10^{-12} \mathrm{~cm}^{2} \mathrm{~s}^{-1}$ are found for lithiation and delithiation, respectively, for which the electrode has the composition of $\mathrm{Li}_{0.34} \mathrm{TiO}_{2}$ (lithiation) and $\mathrm{Li}_{0.49} \mathrm{TiO}_{2}$ (delithiation) The potential where the maxima occur are close to the peak potentials from $\mathrm{CV}$ and the maxima in incremental charge from PITT (Figure 7c). For anatase (Figure $9 \mathrm{~b}$ ) the diffusion coefficient varies between $10^{-11}$ and $10^{-15} \mathrm{~cm}^{2} \mathrm{~s}^{-1}$ depending on the electrode potential, with sharp minima near the insertion (i.e. $\left.2.6 \times 10^{-14} \mathrm{~cm}^{2} \mathrm{~s}^{-1}\right)$ and extraction $(8.8$ $\times 10^{-14} \mathrm{~cm}^{2} \mathrm{~s}^{-1}$ ) peaks. Although values for the diffusion coefficients of am- $\mathrm{TiO}_{2}$ and anatase span the same order of magnitude, near the

peaks of insertion and extraction, the diffusion coefficient of am$\mathrm{TiO}_{2}$ is several orders of magnitude higher. Besides a higher diffusion coefficient, am- $\mathrm{TiO}_{2}$ also shows an internal resistance that is about ten times lower compared to anatase (see Figure S5-6). As can be seen, the PITT analysis allowed the determination of both the diffusion coefficient as well as the internal resistance, while the CV analysis gave only an indication of the limiting process (diffusion or chargetransfer). Note that although the same PITT model was used to fit the current transients for both films, a striking difference in the $D$ versus $U$ relationship is revealed (i.e. a maximum for am- $\mathrm{TiO}_{2}$ and minimum for anatase in $D$ vs $U$ ). The higher diffusion coefficient for am- $\mathrm{TiO}_{2}$ at the peak of $\mathrm{Li}^{+}$-ion insertion/extraction, together with the low charge-transfer resistance, explains the superior performance as seen from $\mathrm{CV}$ and rate-performance experiments.

Lithium insertion/extraction mechanisms.-Based on the previous results, we expect that $\mathrm{Li}^{+}$-ion insertion and extraction mechanism is different for $\mathrm{am}-\mathrm{TiO}_{2}$ than for anatase. First anatase is considered, as it follows a behavior more typical for $\mathrm{Li}^{+}$-ion insertion materials. From the $\mathrm{CV}$ results, $\mathrm{Li}^{+}$-ion insertion kinetics of anatase was found to be dominated by diffusion. A schematic of this process is given in Figure 10a, which shows the Li concentration profile in the electrode during lithiation. Note that the concentration drawn in the schematic considers the insertion of both $\mathrm{Li}^{+}$and the accompanying electron, i.e. the reduced $\mathrm{Ti}(\mathrm{III})$ indicated by $\mathrm{Li}_{\mathrm{x}} \mathrm{Ti}^{4-x} \mathrm{O}_{2}$, and we will refer this combined state as the Li concentration.

In the case of anatase, three different stages can be identified as $x$ (in $\mathrm{Li}_{x} \mathrm{TiO}_{2}$ ) increases:

Solid-solution insertion (i.e. $\boldsymbol{x}<<$ 0.034). - When $\mathrm{TiO}_{2}$ is (nearly) empty $\left(t_{0}\right), \mathrm{Li}^{+}$-ions are inserted via relatively fast solidsolution, leading to a nearly homogenous $\mathrm{Li}$ concentration profile throughout the film. As measured with PITT, the diffusion coefficient is near its maximum for low values of $x\left(>10^{-12} \mathrm{~cm}^{2} \mathrm{~s}^{-1}\right)$. In this case, the characteristic diffusion time $\left(\tau_{D}=1^{2} / D\right)$ is in the order of tens of seconds.

Phase transition $(\mathrm{x} \leq \mathbf{0 . 0 3 4})$. - As $x \rightarrow 0.034$, the diffusion coefficient drops dramatically $\left(<10^{-14} \mathrm{~cm}^{2} \mathrm{~s}^{-1}\right)$ and Li builds up within $\mathrm{TiO}_{2}$ near the electrode/electrolyte interface. A characteristic diffusion time in the order of 1000's of seconds is obtained. As $\mathrm{x}=0.034$ $\left(t_{2}\right)$, phase-transition initiates segregation of Li-ions at the top of the electrodes to form a $\mathrm{Li}$-rich orthorhombic $\mathrm{Li}_{0.5} \mathrm{TiO}_{2}$ domain. Any additional $\mathrm{Li}$ moves the Li-rich phase further into the empty $\mathrm{TiO}_{2}$ phase $\left(t_{3}\right)$.

Lithium accumulation at the top of the electrode $(x>0.034)$. If the $\mathrm{Li}$ flux into $\mathrm{TiO}_{2}$ is higher than the moving $\mathrm{Li}_{0.5} \mathrm{TiO}_{2}$ phase can (a)

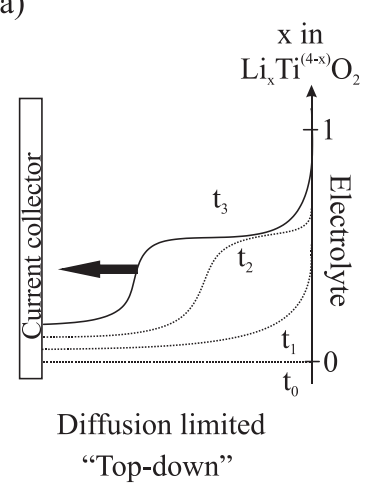

(b)

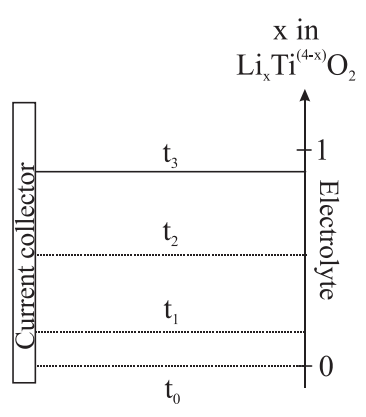

Equilibrium filling (c)

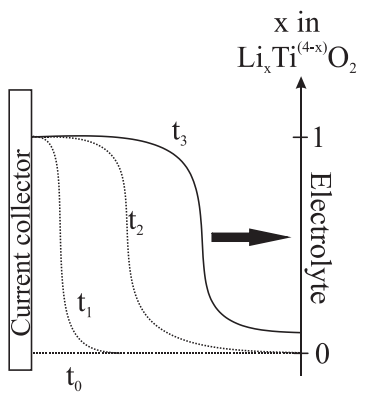

Charge transfer limited

"Bottom-up"

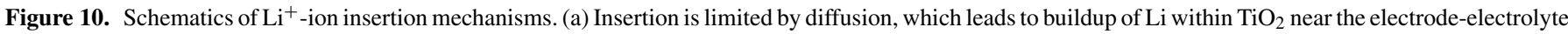

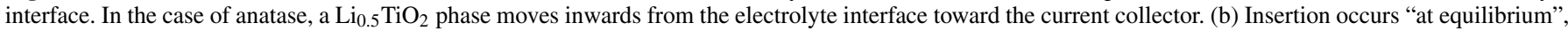

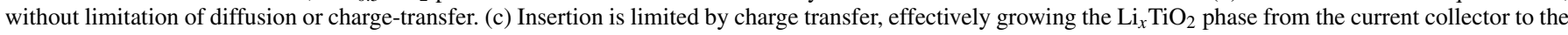
electrolyte interface. 
accommodate, $\mathrm{Li}$ will further accumulate at the top of the electrode near the electrode/electrolyte interface $\left(t_{3}\right)$. It is known for anatase that an increase in the $\mathrm{Li}$ concentration (above $\mathrm{Li}_{0.5} \mathrm{TiO}_{2}$ ) can lead to a second phase transition (i.e. $\mathrm{LiTiO}_{2}$ ), resulting in an additional orders of magnitude reduction in Li-ion diffusion coefficient. ${ }^{44-46}$ The formation of a blocking $\mathrm{LiTiO}_{2}$ domain is considered the main reason for the limited insertion capacity of anatase.

In general, an insertion mechanism where a small increase in Li concentration leads to a sharp decrease in diffusion coefficient, likely forms a blocking interface near the surface (i.e. at the electrode/electrolyte side). In other words, such a mechanism can be considered a "top-down" filling mechanism. As any additional lithium will further decrease its diffusion, such a mechanism can be considered self-limiting and prevents full capacity utilization of the electrode. Such a top-down insertion mechanism has also been formulated before for "thick" anatase $\mathrm{TiO}_{2}$ films $(135 \mathrm{~nm})$ based on optical and electrochemical results. ${ }^{28}$

Next, it is useful to consider the ideal case of insertion under (near-) equilibrium conditions (Figure $10 \mathrm{~b}$ ). If $\mathrm{Li}$ is inserted slowly and without phase-transition, homogenous distribution of Li-ions throughout the electrode can be obtained. At each time $\left(t_{1-3}\right)$, the concentration of $\mathrm{Li}$ is (nearly) equal across the electrode. This requirement is likely fulfilled for $\mathrm{am}-\mathrm{TiO}_{2}$ during $\mathrm{CV}$ scans performed at low scan rate (i.e. $1 \mathrm{mV} \mathrm{s}^{-1}$ ), since the analysis neither showed diffusion limitations (Figure 4a) nor any influence of overpotentials (Figure 4b).

However, as seen from the $\mathrm{CV}$ analysis of $\mathrm{am}-\mathrm{TiO}_{2}$ for higher scan rates, although there was no indication of diffusion limitation, an increasing overpotential was measured. In a system purely controlled by charge transfer kinetics, the overpotential in $\mathrm{CV}$ should have a logarithmic dependence on the peak current. In our case, a linear relationship between the peak current and overpotential was measured. From this relationship, an "ohmic" resistance was calculated of about $1.2 \mathrm{k} \Omega \mathrm{cm}^{-2}$. This value corresponds quite well with the internal resistance determined using PITT (see Figure S5b) for am- $\mathrm{TiO}_{2}$. This suggests that the largest contribution to the internal resistance is the electrode resistance $\left(R_{\mathrm{e}}\right)$, as this would also follow an ohmic behavior.

For our thin-film electrodes, during Li-ion insertion, the corresponding electrons are introduced via the current-collector. If the electronic conductivity is higher than the ionic conductivity, association of $\mathrm{Li}^{+}$with an electron $\left(\mathrm{e}^{-}\right)$occurs near electrode/electrolyte interface, as in the case of anatase $\mathrm{TiO}_{2}$. The neutral $\mathrm{Li}^{+} / \mathrm{e}^{-}$pair is then primarily transported through the film via diffusion. However, it is known that $\mathrm{am}-\mathrm{TiO}_{2}$ has typically a lower electrical conductivity compared to anatase. ${ }^{47}$ Combined with the fact that $\mathrm{am}-\mathrm{TiO}_{2}$ has a higher diffusion coefficient than anatase, a different insertion mechanism is possible. In this case, association of $\mathrm{Li}^{+}$with $\mathrm{e}^{-}$occurs near the current-collector/electrode interface. $\mathrm{Li}^{+}$is then transported through the film via migration and associates with $\mathrm{e}^{-}$near the currentcollector.

This situation for am- $\mathrm{TiO}_{2}$ can be considered a "bottom-up" fill mechanism, as the $\mathrm{Li}$ concentration (i.e. $\mathrm{Li}^{+} / \mathrm{e}^{-}$pair) grows from the current-collector/electrode to the electrode/electrolyte interface. The benefit of such an insertion mechanism is that $\mathrm{Li}^{+}$are continuously transported through an "empty" $\mathrm{TiO}_{2}$ phase. As the diffusion coefficient drops several orders of magnitude as $\mathrm{x} \rightarrow 1$, increasing the $\mathrm{Li}$ concentration from the bottom up is the most efficient way to fill the electrode. A schematic showing the bottom-up fill is given in Figure 10c. At $t_{1}, \mathrm{Li}$-ions are transported toward the current collector, and associate with the electron to form the $\mathrm{Li}_{x} \mathrm{TiO}_{2}$ phase. In this case, $\mathrm{LiTiO}_{2}$ forms at the bottom, and as more Li-ions are inserted $\left(t_{2}\right)$, the $\mathrm{LiTiO}_{2}$ phase grows upwards, until it starts to reach the electrolyte $\left(t_{3}\right)$.

A similar phenomena has been observed for delithiation of $\mathrm{LiFePO}_{4}$ in a solid-state microbattery using scanning transmission X-ray microscopy. ${ }^{48}$ By following the $\mathrm{Fe}^{2+} / \mathrm{Fe}^{3+}$ states within the electrode using X-ray Absorption Near Edge Structure (XANES), the delithiation/lithiation could be followed microscopically. It was shown that during delithiation of $\mathrm{LiFePO}_{4}$, the $\mathrm{FePO}_{4}$ phase grew from the current-collector toward to solid-electrolyte; opposite of what would be expected based on a purely diffusion controlled process. This was explained by the faster Li-ion conductivity within $\mathrm{LiFePO}_{4}$ compared to the electron conductivity. Similar to our case, the enhanced Li-ion conductivity relative to its electron conductivity will lead to a filling mechanism which occurs opposite of where $\mathrm{Li}^{+}$is inserted. To further support this hypothesis, it would be interesting to perform in situ XANES with am- $\mathrm{TiO}_{2}$ films and follow the $\mathrm{Ti}^{3+} / \mathrm{Ti}^{4+}$ states during lithiation/delithiation.

\section{Conclusions}

Amorphous and anatase thin-films were deposited using ALD and characterized for their $\mathrm{Li}^{+}$-ion insertion properties. From ERDA, differences in composition between $\mathrm{am}-\mathrm{TiO}_{2}$ and anatase were found, with am- $\mathrm{TiO}_{2}$ having a higher impurity content of $\mathrm{H}, \mathrm{C}$ and $\mathrm{N}$. This is likely a result of the low deposition temperature used (i.e. $100^{\circ} \mathrm{C}$ ), which was needed to ensure the amorphous nature of the films. During electrochemical testing it was found that an activation step was necessary to obtain good Li-ion insertion properties for am- $\mathrm{TiO}_{2}$. Only when applying a voltage below $1 \mathrm{~V} \mathrm{vs} \mathrm{Li}^{+} / \mathrm{Li}$ was the am- $-\mathrm{TiO}_{2}$ fully activated. $\mathrm{CV}$ experiments revealed a different insertion mechanism between $\mathrm{am}-\mathrm{TiO}_{2}$ and anatase. Whereas a diffusion limited process was measured for anatase, insertion for am- $\mathrm{TiO}_{2}$ proceeded un-restricted by diffusion. Furthermore, a significantly higher overpotential was required for insertion into anatase compared to $\mathrm{am}-\mathrm{TiO}_{2}$. Constant current lithiation and delithiation experiments revealed a volumetric capacity of am- $\mathrm{TiO}_{2}$ that was three times the anatase capacity. An exceptional rate-performance was obtained for $35 \mathrm{~nm}$ films, with $67 \%$ of the maximum capacity reached at a rate of $115 \mathrm{C}$. The rate-performance was further improved by decreasing the film thickness to 10 or $5 \mathrm{~nm} \mathrm{TiO}{ }_{2}$. For the $5 \mathrm{~nm}$ film, the accessible capacity at $500 \mathrm{C}$ was $266 \mathrm{mAh} \mathrm{cm}^{-3}$ or $116 \mathrm{mAh} \mathrm{g}^{-1}$, which was $54 \%$ its maximum capacity. PITT experiments probed the near-equilibrium thermodynamic and kinetic properties of lithiation and delithiation in am- $\mathrm{TiO}_{2}$ and anatase. While am- $\mathrm{TiO}_{2}$ shows lithium insertion and extraction almost across the whole $3.0-0.1 \mathrm{~V}$ range, most of the lithiation and delithiation for anatase occurs across near $1.78 \mathrm{~V}$ and 1.90 $\mathrm{V}$, respectively. Solid-state $\mathrm{Li}^{+}$-ion diffusion coefficients and internal electrode resistances were obtained after fitting of PITT current transients to equivalent circuit models. A different trend in $D$ vs $U$ was observed between anatase and $\mathrm{am}-\mathrm{TiO}_{2}$. Using the combination of electrochemical analysis techniques, two different insertion mechanisms were formulated for anatase and am- $\mathrm{TiO}_{2}$. The sluggish $\mathrm{Li}^{+}$diffusion in anatase leads to a buildup of $\mathrm{Li}_{x} \mathrm{TiO}_{2}$ near the electrode/electrolyte interface, leading to a top-down filling mechanism. In contrast, am- $\mathrm{TiO}_{2}$ shows fast $\mathrm{Li}^{+}$diffusion which leads to the buildup of $\mathrm{Li}_{x} \mathrm{TiO}_{2}$ from the bottom up, and helps to explain its superior charging capabilities. This work highlights am- $\mathrm{TiO}_{2}$ as a high rate anode material and shows the benefits of using the amorphous $\mathrm{TiO}_{2}$ structure.

\section{Acknowledgments}

Dr. Shaoren Deng (UGent), under supervision of Prof. Christophe Detavernier (UGent), for ALD of amorphous $\mathrm{TiO}_{2}$ on TiN substrates. S. M. gratefully acknowledges the support of a Ph.D. stipend from the Agency for Innovation by Science and Technology in Flanders (IWT).

\section{ORCID}

S. Moitzheim (1) https://orcid.org/0000-0003-4773-9796

S. De Gendt (D) https://orcid.org/0000-0003-3775-3578

\section{References}

1. G. Lui, G. Li, X. Wang, G. Jiang, E. Lin, M. Fowler, A. Yu, and Z. Chen, Flexible, Three-Dimensional Ordered Macroporous $\mathrm{TiO}_{2}$ Electrode with Enhanced Electrodeelectrolyte Interaction in High-Power Li-Ion Batteries, Nano Energy, 24, 72 (2016). 
2. J. Ye, A. C. Baumgaertel, Y. M. Wang, J. Biener, M. M. Biener, M. Monika, M. M. Biener, and M. Monika, Structural Optimization of 3D Porous Electrodes for High-Rate Performance Lithium Ion Batteries, ACS Nano, 9, 2194 (2015).

3. H. Yang, C.-K. Lan, and J.-G. Duh, The Power of Nb-Substituted $\mathrm{TiO}_{2}$ in Li-Ion Batteries: Morphology Transformation Induced by High Concentration Substitution, J. Power Sources, 288, 401 (2015).

4. W. Li, D. Corradini, M. Body, C. Legein, M. Salanne, J. Ma, K. W. Chapman, P. J. Chupas, A.-L. Rollet, C. Julien, K. Zhagib, M. Duttine, A. Demourgues, H. Groult, and D. Dambournet, High Substitution Rate in $\mathrm{TiO}_{2}$ Anatase Nanoparticles with Cationic Vacancies for Fast Lithium Storage, Chem. Mater, 27, 5014 (2015).

5. Y. Shen, J. S. Chen, J. Zhu, Q. Yan, and X. Hu, Growth of Two-Dimensional Ultrathin Anatase $\mathrm{TiO}_{2}$ Nanoplatelets on Graphene for High-Performance Lithium-Ion Battery, J. Nanoparticle Res, 15, 1913 (2013).

6. J. Liu, J. S. Chen, X. Wei, X. W. Lou, and X. Liu, Sandwich-Like, Stacked Ultrathin Titanate Nanosheets for Ultrafast Lithium Storage, Adv. Mater., 23, 998 (2011).

7. G. Armstrong, A. R. Armstrong, P. G. Bruce, P. Reale, and B. Scrosati, $\mathrm{TiO}_{2}(\mathrm{~B})$ Nanowires as an Improved Anode Material for Lithium-Ion Batteries Containing $\mathrm{LiFePO}_{4}$ or $\mathrm{LiNi}_{0.5} \mathrm{Mn}_{1.5} \mathrm{O}_{4}$ Cathodes and a Polymer Electrolyte. Adv. Mater., 18, 2597 (2006).

8. H. Xiong, H. Yildirim, E. V Shevchenko, V. B. Prakapenka, B. Koo, M. D. Slater, M. Balasubramanian, S. K. R. S. Sankaranarayanan, J. P. Greeley, S. Tepavcevic, N. M. Dimitrijevic, P. Podsiadlo, C. S. Johnson, and T. Rajh, Self-Improving Anode for Lithium-Ion Batteries Based on Amorphous to Cubic Phase Transition in $\mathrm{TiO}_{2}$ Nanotubes, J. Phys. Chem. C, 116, 3181 (2012).

9. H. Fang, M. Liu, D. Wang, T. Sun, D.-S. Guan, F. Li, J. Zhou, T.-K. Sham, and H.-M. Cheng, Comparison of the Rate Capability of Nanostructured Amorphous and Anatase $\mathrm{TiO}_{2}$ for Lithium Insertion Using Anodic $\mathrm{TiO}_{2}$ Nanotube Arrays, Nanotechnology, 20, 225701 (2009)

10. W. J. H. Borghols, D. Lützenkirchen-Hecht, U. Haake, W. Chan, U. Lafont E. M. Kelder, E. R. H van Eck, A.P.M. Kentgens, F. M. Mulder, an M. Wagemaker, Lithium Storage in Amorphous $\mathrm{TiO}_{2}$ Nanoparticles, J. Electrochem. Soc., 157, A582 (2010)

11. S. Moitzheim, J. E. Balder, P. Poodt, S. Unnikrishnan, S. De Gendt, and P. M. Vereecken, Chlorine Doping of Amorphous $\mathrm{TiO}_{2}$ for Increased Capacity and Faster $\mathrm{Li}^{+}$-Ion Storage, Chem. Mater, 29, 10007 (2017).

12. S. Moitzheim, C. S. Nimisha, S. Deng, D. J. Cott, C. Detavernier, and P. M. Vereecken, Nanostructured $\mathrm{TiO}_{2} /$ Carbon Nanosheet Hybrid Electrode for HighRate Thin-Film Lithium-Ion Batteries, Nanotechnology, 25, 504008 (2014).

13. M. Li, X. Li, W. Li, X. Meng, Y. Yu, and X. Sun, Atomic Layer Deposition Derived Amorphous $\mathrm{TiO}_{2}$ Thin Film Decorating Graphene Nanosheets with Superior Rate Capability, Electrochem. commun., 57, 43 (2015).

14. M. Xie, X. Sun, C. Zhou, A. S. Cavanagh, H. Sun, T. Hu, G. Wang, J. Lian, and S. M. George, Amorphous Ultrathin $\mathrm{TiO}_{2}$ Atomic Layer Deposition Films on Carbon Nanotubes as Anodes for Lithium Ion Batteries, J. Electrochem. Soc, 162, A974 (2015).

15. X. H. Wang, C. Guan, L. M. Sun, R. A. Susantyoko, H. J. Fan, and Q. Zhang, Highly Stable and Flexible Li-Ion Battery Anodes Based on $\mathrm{TiO}_{2}$ Coated 3D Carbon Nanostructures, J. Mater. Chem. A, 3, 15394 (2015).

16. J. Song and W. West, All Solid-State Thin Film Batteries, In Handbook of Solid State Batteries, N. J. Dudney, W. C. West, J. Nanda, Eds.; Materials and Energy; World Scientific, 2015; Vol. 6, pp 591

17. Y. Chen, Y. Zhang, B. Chen, Z. Wang, and C. Lu, An Approach to Application for $\mathrm{LiNi}_{0.6} \mathrm{Co}_{0.2} \mathrm{Mn}_{0.2} \mathrm{O}_{2}$ Cathode Material at High Cutoff Voltage by $\mathrm{TiO}_{2}$ Coating, J. Power Sources, 256, 20 (2014)

18. W. Liu, M. Wang, X. L. Gao, W. Zhang, J. Chen, H. Zhou, and X. Zhang, Improvement of the High-Temperature, High-Voltage Cycling Performance of $\mathrm{LiNi}_{0.5} \mathrm{Co}_{0.2} \mathrm{Mn}_{0.3} \mathrm{O}_{2}$ Cathode with $\mathrm{TiO}_{2}$ Coating, J. Alloys Compd., 543, 181 (2012).

19. H. C. M. Knoops, L. Baggetto, E. Langereis, M. C. M. van de Sanden, J. H. Klootwijk, F. Roozeboom, R. A. H. Niessen, P. H. L. Notten, and W. M. M. Kessels, Deposition of TiN and TaN by Remote Plasma ALD for $\mathrm{Cu}$ and Li Diffusion Barrier Applications, J. Electrochem. Soc., 155, G287 (2008)

20. Q. Xie, Y.-L. Jiang, C. Detavernier, D. Deduytsche, R. L. Van Meirhaeghe, G.-P. Ru, B.-Z. Li, and X.-P. Qu, Atomic Layer Deposition of $\mathrm{TiO}_{2}$ from Tetrakis-DimethylAmido Titanium or Ti Isopropoxide Precursors and $\mathrm{H}_{2} \mathrm{O}$, J. Appl. Phys., 102, 083521 (2007).

21. V. Pore, A. Rahtu, M. Leskelä, M. Ritala, T. Sajavaara, and J. Keinonen, Atomic Layer Deposition of Photocatalytic $\mathrm{TiO}_{2}$ Thin Films from Titanium Tetramethoxide and Water, Chem. Vap. Depos., 10, 143 (2004).

22. S. Giangrandi, T. Sajavaara, B. Brijs, K. Arstila, A. Vantomme, and W. Vandervorst, Low-Energy Heavy-Ion TOF-ERDA Setup for Quantitative Depth Profiling of Thin Films, Nucl. Instruments Methods Phys. Res. B, 266, 5144 (2008).

23. M. Laitinen, M. Rossi, J. Julin, and T. Sajavaara,Time-of-Flight - Energy Spectrometer for Elemental Depth Profiling - Jyväskylä Design, Nucl. Instruments Methods Phys. Res. B, 337, 55 (2014).
24. C. R. Ottermann and K. Bange, Correlation between the Density of $\mathrm{TiO}_{2}$ Films and Their Properties, Thin Solid Films, 286, 32 (1996).

25. J. S. Chen and X. W. Lou, Anatase $\mathrm{TiO}_{2}$ Nanosheet: An Ideal Host Structure for Fast and Efficient Lithium Insertion/Extraction, Electrochem. commun., 11, 2332 (2009).

26. T. Dobbelaere, F. Mattelaer, J. Dendooven, P. Vereecken, and C. Detavernier, PlasmaEnhanced Atomic Layer Deposition of Iron Phosphate as a Positive Electrode for 3D Lithium-Ion Microbatteries, Chem. Mater, 28, 3435 (2016).

27. K. B. Gandrud, A. Pettersen, O. Nilsen, and H. Fjellvåg, High-Performing Iron Phosphate for Enhanced Lithium Ion Solid State Batteries as Grown by Atomic Layer Deposition, J. Mater. Chem. A, 1, 9054 (2013).

28. R. van de Krol, A. Goossens, J. Schoonman, R. Van De Krol, A. Goossens, J. Schoonman, R. van de Krol, A. Goossens, and J. Schoonman, Spatial Extent of Lithium Intercalation in Anatase $\mathrm{TiO}_{2}$, J. Phys. Chem. B, 103, 7151 (1999).

29. K. Aoki, K. Tokuda, and H. Matsuda, Theory of Linear Sweep Voltammetry with Finite Diffusion Space, J. Electroanal. Chem. Interfacial Electrochem., 160, 33 (1984).

30. S.-I. Pyun, H.-C. Shin, J.-W. Lee, J.-Y. Go, and Electrochemical Methods, In Electrochemistry of Insertion Materials for Hydrogen and Lithium, F. Scholz, Ed., SpringerVerlag: Heidelberg, 2012, pp 11.

31. M. Wagemaker, W. J. H. Borghols, and F. M. Mulder, Large Impact of Particle Size on Insertion Reactions. A Case for Anatase $\mathrm{Li}_{x} \mathrm{TiO}_{2}$, J. Am. Chem. Soc., 129, 4323 (2007).

32. M. D. Levi and D. Aurbach, Potentiostatic and Galvanostatic Intermittent Titration Techniques. In Characterization of Materials, E. N. Kaufmann, Ed., John Wiley \& Sons: Hoboken, 2012, pp 913.

33. C. J. Wen, B. A. Boukamp, R. A. Huggins, and W. Weppner, Thermodynamic and Mass Transport Properties of "LiAl." J. Electrochem. Soc., 126, 2258 (1979).

34. M. Levi and D. Aurbach, Frumkin Intercalation Isotherm - a Tool for the Description of Lithium Insertion into Host Materials: A Review, Electrochim. Acta, 45, 167 (1999).

35. C. Montella, Apparent Diffusion Coefficient of Intercalated Species Measured with PITT: A Simple Formulation, Electrochim. Acta, 51, 3102 (2006).

36. M. A. Vorotyntsev, M. D. Levi, and D. Aurbach, Spatially Limited Diffusion Coupled with ohmic Potential Drop and/or Slow Interfacial Exchange: A New Method to Determine the Diffusion Time Constant and External Resistance from Potential Step (PITT) Experiments, J. Electroanal. Chem., 572, 299 (2004).

37. M. D. Levi, R. Demadrille, A. Pron, M. A. Vorotyntsev, Y. Gofer, and D. Aurbach, Application of a Novel Refinement Method for Accurate Determination of Chemical Diffusion Coefficients in Electroactive Materials by Potential Step Technique, J. Electrochem. Soc., 152, E61 (2005).

38. C. Montella and J.-P. Diard, New Approach of Electrochemical Systems Dynamics in the Time-Domain under Small-Signal Conditions. I. A Family of Algorithms Based on Numerical Inversion of Laplace Transforms, J. Electroanal. Chem., 623, 29 (2008)

39. C. Montella, Re-Examination of the Potential-Step Chronoamperometry Method through Numerical Inversion of Laplace Transforms. I. General Formulation and Numerical Solution, J. Electroanal. Chem., 633, 35 (2009).

40. C. Montella, Re-Examination of the Potential Step Chronoamperometry Method through Numerical Inversion of Laplace Transforms. II. Application Examples. J. Electroanal. Chem., 633, 45 (2009).

41. Mathematica Version, 10.2. Wolfram Research: Champaign, IL 2015

42. C. Montella and R. Michel, New Approach of Electrochemical Systems Dynamics in the Time Domain under Small-Signal Conditions: III - Discrimination between Nine Candidate Models for Analysis of PITT Experimental Data from $\mathrm{Li}_{x} \mathrm{CoO}_{2}$ Film Electrodes, J. Electroanal. Chem., 628, 97 (2009).

43. J. S. Chen, J.-P. Diard, R. Durand, and C. Montella, Hydrogen Insertion Reaction with Restricted Diffusion. Part 1. Potential Step-EIS Theory and Review for the Direct Insertion Mechanism, J. Electroanal. Chem., 406, 1 (1996).

44. M. Koudriachova, N. Harrison, and S. de Leeuw, Effect of Diffusion on Lithium Intercalation in Titanium Dioxide, Phys. Rev. Lett., 86, 1275 (2001).

45. A. A. Belak, Y. Wang, and A. Van der Ven, Kinetics of Anatase Electrodes: The Role of Ordering, Anisotropy, and Shape Memory Effects, Chem. Mater, 24, 2894 (2012).

46. M. Wagemaker, D. Lützenkirchen-Hecht, A. A. van Well, and R. Frahm,Atomic and Electronic Bulk versus Surface Structure: Lithium Intercalation in Anatase $\mathrm{TiO}_{2}$, J. Phys. Chem. B, 108, 12456 (2004).

47. W. S. Shih, S. J. Young, L. W. Ji, W. Water, and H. W. Shiu, $\mathrm{TiO}_{2}-\mathrm{Based}_{\text {Thin Film }}$ Transistors with Amorphous and Anatase Channel Layer, J. Electrochem. Soc., 158, H609 (2011).

48. N. Ohmer, B. Fenk, D. Samuelis, C. Chen, J. Maier, M. Weigand, E. Goering, and G. Schu, Phase Evolution in Single-Crystalline $\mathrm{LiFePO}_{4}$ Followed by in Situ Scanning X-Ray Microscopy of a Micrometre-Sized Battery, Nat. Commun., 6, 1 (2015). 